\title{
Intracerebroventricular injections of dronabinol, a cannabinoid receptor agonist, does not attenuate serotonin-induced apnea in Sprague-Dawley rats
}

Michael W. Calik ${ }^{1,2^{*}}$ and David W. Carley ${ }^{1,2,3}$

\begin{abstract}
Background: Evidence suggests that vagal nerve activity may play a role in sleep apnea induction. In anesthetized rats, dronabinol, a cannabinoid (CB) receptor agonist, injected into the nodose ganglia attenuates reflex apnea and increases genioglossus activity, and reflex apnea attenuation is blocked by systemic pre-treatment with cannabinoid type 1 and/or type 2 receptor antagonists. However, it is unclear whether dronabinol has similar effects in the central nervous system; CB receptors are widely distributed in the brain, especially on neuronal circuitry important for respiration and upper airway activation. Here, we examine the effects of intracerebroventricular (ICV) injection of dronabinol on serotonin (5-HT)-induced apnea.
\end{abstract}

Methods: Adult male Sprague-Dawley rats were anesthetized and instrumented with bilateral electrodes to monitor genioglossi EMG and with a piezoelectric strain gauge to monitor respiratory pattern. Serotonin was intravenously infused into a femoral vein to induce reflex apnea. After baseline recordings, rats were placed in a stereotaxic apparatus. A unilateral osteotomy was made to allow access for injection to the right lateral ventricle, and the dura were carefully removed. Dronabinol $(100,10$, 1, or $0.1 \mu \mathrm{g} / 3 \mu \mathrm{l}$ DMSO) or control (3 $\mu \mathrm{l}$ DMSO) was injected into the right lateral ventricle and $5-\mathrm{HT}$ infusion was repeated. Data (mean \pm SEM) were analyzed using a mixed model analysis with a repeated/fixed measure.

Results: There was no main effect in 5-HT-induced apnea or breath duration, or in breath instability, between ICV dronabinol injected and ICV vehicle control injected groups. Moreover, there was no main effect in phasic or tonic genioglossus activity between ICV dronabinol injected and ICV vehicle control injected groups.

Conclusion: Our data show that ICV injection of dronabinol did not decrease 5-HT-induced apneas, and did not increase genioglossus activity. This in contrast to published results of dronabinol's effect on apnea via the vagus nerve. Our results suggest that the effects of dronabinol on reflex apneas are peripherally mediated via suppression of vagal nerve activity.

Keywords: Dronabinol, Cannabinoids, Obstructive sleep apnea, Reflex apnea, Serotonin, Intracerebroventricular injection

\footnotetext{
* Correspondence: mcalik@uic.edu

${ }^{1}$ Center for Narcolepsy, Sleep and Health Research, University of Illinois at

Chicago, 845 South Damen Avenue (M/C 802), Chicago, IL 60612, USA

${ }^{2}$ Department of Biobehavioral Health Science, University of Illinois at

Chicago, 845 South Damen Avenue (M/C 802), Chicago, IL 60612, USA

Full list of author information is available at the end of the article
} 


\section{Background}

Obstructive sleep apnea (OSA), characterized by a cessation of breathing produced by a narrowed or collapsed upper airway, represents a significant public health risk $[1,2]$. Current OSA prevalence estimates indicate that $14 \%$ of American men and $5 \%$ of American women suffer from OSA, and that those estimates are rising [1]. More importantly, there are strong associations between OSA and other diseases, such as type 2 diabetes, hypertension, stroke, and coronary heart disease [3-5]. The "gold standard" of OSA treatment is to splint open the upper airway via continuous positive air pressure; however, treatment tolerance is low and patients do not adhere to treatment despite obvious health benefits [2] Safe and effective pharmacological treatments for OSA remain to be identified, and such efforts have been limited by incomplete knowledge of the central and peripheral neural mechanisms controlling respiration during sleep $[2,6]$. Recently, activating the inhibitory $G_{i / o}$-associated cannabinoid (CB) receptors have been proposed as novel pharmacological intervention to treat OSA $[7,8]$.

The endocannabinoid system, associated with cannabinoid type $1\left(\mathrm{CB}_{1}\right)$ and cannabinoid type $2\left(\mathrm{CB}_{2}\right)$ receptors located on peripheral nerves and central neurons, can be targeted therapeutically to modify disease states $[9,10]$. Dronabinol, a synthetic version of $\Delta 9$ $\mathrm{THC}$, is a FDA-approved $\mathrm{CB}_{1}$ and $\mathrm{CB}_{2}$ receptor agonist used to suppress chemotherapy-induced nausea and stimulate appetite in AIDS patients [11]. Dronabinol, when administered to patients with OSA [12], or to rats chronically-instrumented to measure respiration during sleep [13], decreased apneas. The mechanism of dronabinol's effect in decreasing apnea propensity appeared to be, in part, due to the activation of both $C_{1}$ and $C_{2}$ receptors located on nodose ganglia of the vagus nerves $[14,15]$, which transmit vital information from the lungs to the brainstem, contributing to reflex responses regulating: tidal volume, respiratory frequency, augmented breaths and bronchoconstriction [16, 17]. In a wellestablished model of vagally-mediated reflex apnea [18], dronabinol injected into nodose ganglia attenuated apneas [15]. Antagonism of $\mathrm{CB}_{1}, \mathrm{CB}_{2}$, or both reversed dronabinol's attenuation of apneas [14]. More importantly, dronabinol also increased phasic upper airway activity via activation of $\mathrm{CB}$ receptors at the nodose ganglia $[14,15]$. Though recent evidence confirms the role the vagus nerve plays in apnea propensity $[14,15$, 19-21], less is known about the role that central $C B$ receptors have in apnea induction or suppression. Dronabinol is highly lipophilic and readily crosses the bloodbrain barrier into the central nervous system [22], where CB receptors are widely distributed [23, 24] [10], including brain areas vital to respiratory control [23, 25-28]. Complicating the issue further is that activating central $\mathrm{CB}$ receptors can inhibit evoked release of excitatory or inhibitory neurotransmitters [29], thereby inhibiting or disinhibiting neuronal activity [9, 30]. It is unknown if central versus peripheral administration of a $\mathrm{CB}$ agonist would have similar or dissimilar effects on respiration. Therefore, it is important to understand dronabinol's global effects on the central nervous system without activating $\mathrm{CB}$ receptors in the peripheral nervous system.

Here, we hypothesized that global central administration via intracerebroventricular (ICV) injection of dronabinol would attenuate reflex apneas and increase upper airway activity.

\section{Methods}

\section{Animals}

Thirty adult male Sprague-Dawley rats (275-300 g) were purchased from Harlan Laboratories (Indianapolis, IN, USA), housed in duplicate, maintained on a 12:12 light:dark cycle at $22 \pm 0.5{ }^{\circ} \mathrm{C}$, and allowed ad libitum access to food and water. All animal procedures and protocols were approved by the Institutional Animal Care and Use Committee of the University of Illinois at Chicago (Protocol no.: 11-217/14-159).

\section{Acute ICV injection experiment paradigm}

Rats $(N=30)$ were anesthetized (IP ketamine:xylazine 100:10 mg/kg; IP redosing 100:5 mg/kg; surgical plane of anesthesia was monitored by toe pinch) and instrumented with bilateral electrodes to monitor genioglossus EMG (EMGgg; $1 \mathrm{~mm}$ lateral to the midline) and with a piezoelectric strain gauge to monitor respiratory pattern. The femoral vein was cannulated for $5-\mathrm{HT}(12.5 \mu \mathrm{g} / \mathrm{kg}$; MP Biomedicals, Solon, OH, USA) in PBS (pH 7.4; $0.35 \mathrm{ml} / \mathrm{kg})$ infusions via an infusion pump $(63 \mathrm{ml} / \mathrm{h}$; KD Scientific, Holliston, MA, USA) to induce reflex apneas (repeated a minimum of two times). After baseline recordings $(N=30)$, the head of the rat was mounted in a stereotaxic frame, and dorsal craniotomy was performed to allow for right ICV injections of dronabinol (10 mg capsules, Marinol, Abbvie Inc., North Chicago, IL, USA) at various concentrations $(100,10,1$, or $0.1 \mu \mathrm{g} /$ $3 \mu \mathrm{DMSO} ; \mathrm{N}=6$ for each concentration) or vehicle control (3 $\mu \mathrm{l} \mathrm{DMSO} ; N=6)$ using a 28 gauge needle. Dronabinol ICV doses were chosen based on other physiological effects of various $\triangle 9-T H C$ ICV doses [31-34]. After ICV injections over a minimum $3 \mathrm{~min}$ period, 5-HT infusions were performed again to induce reflex apneas (repeated a minimum of two times).

\section{Data recording and processing}

Data recording and processing have been described before $[14,15]$. Briefly, during EMGgg and respiratory data acquisition, signals were amplified and band-passed filtered (10-240 Hz and 1-10 Hz, respectively; CyberAmp 380, 
Axon Instruments, Sunnyvale, CA, USA), digitized at $500 \mathrm{~Hz}$ (Data Acquisition Subsystems, DataWave Technologies, Loveland, CO, USA), and recorded and saved using SciWorks Experimenter software (DataWave Technologies, Loveland, CO, USA). After recording, EMGgg data were rectified and smoothed (time constant of $100 \mathrm{~ms}$ ) using Spike2 software (Cambridge Electronic Design, Cambridge, England). Tonic EMGgg was defined as the nadir of smoothed expiratory genioglossus activity. Phasic EMGgg was defined as the peak of smoothed inspiratory genioglossus activity minus tonic EMGgg. EMGgg signals after ICV injections were normalized by dividing by EMGgg signals recorded before ICV injections, and are reported as arbitrary units (a.u.). Breath durations, and phasic and tonic EMGgg amplitudes were averaged from 5 previous breaths before IV 5-HT infusion; this was repeated a minimum of two times and averaged. Apnea durations were defined as the average of the longest breath durations lasting at least 2.5 seconds [13] within 30 seconds following IV 5-HT infusion. For measurement of respiratory instability [35], coefficient of variation was calculated for 30 breath durations before and after injection of $5-\mathrm{HT}$.

\section{Statistical analysis}

Data (mean \pm SEM) were analyzed using IBM SPSS Statistics 22 (New York, NY, USA) mixed model analysis with a repeated/fixed measure (ICV treatment) or twoway repeated/fixed measure (time $\times$ ICV treatment) followed by post hoc multiple comparison tests with Sidak's correction if there was a significant main effect. Repeated covariance structure was chosen according to the best-fit Schwarz's Bayesian information criterion. Statistical significance was set at $p<0.05$.

\section{Results}

Reflex apneas induced via IV infusion of 5-HT were conducted in rats before and after ICV injections of various concentrations of dronabinol (Fig. 1). Also, breath duration, coefficient of breath durations, and phasic and tonic genioglossus activity were quantified before and after ICV injections of various concentrations of dronabinol (Figs. 2, 3, and 4, respectively).

At baseline (before ICV injections), IV 5-HT infusion produced reflex apneas lasting $7.29 \pm 0.75$ seconds $(N=30)$. ICV injections of $100 \mu \mathrm{g}(11.80 \pm 2.66$ seconds, $N=6), 10 \mu \mathrm{g}(7.73 \pm 0.85$ seconds, $N=6), 1 \mu \mathrm{g}(7.48 \pm$ 0.87 seconds, $N=6)$, or $0.1 \mu \mathrm{g}(9.67 \pm 1.46$ seconds, $N=6)$ of dronabinol, or injection of vehicle (DMSO; 7.79 \pm 0.93 seconds, $N=6)$ did not significantly $\left(F_{5}, 35.6=1.90\right.$, $p=0.12$ for main effect of "treatment") alter apnea durations compared to baseline (Fig. 1).

Breath durations were averaged from 5 breaths prior to 5-HT-induced apneas. Average breath duration before ICV injections was $0.89 \pm 0.03$ seconds $(N=30)$, and was

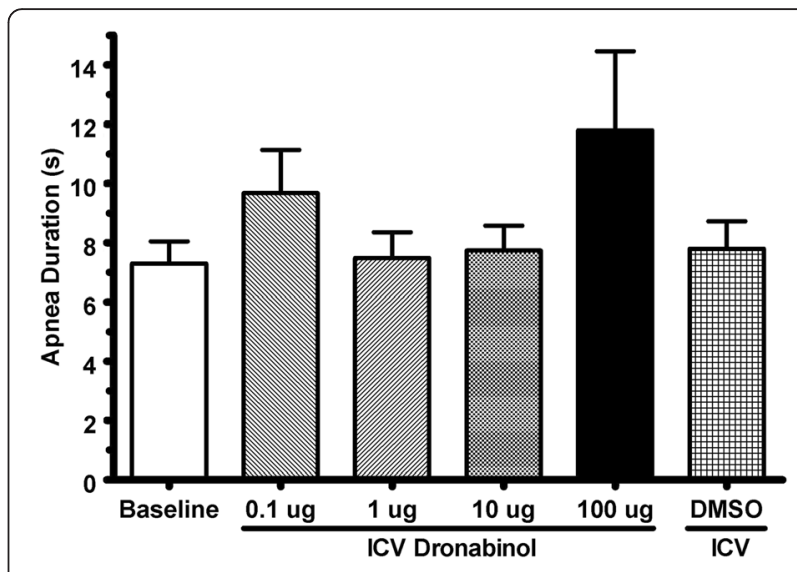

Fig. 1 Apnea duration quantified from acute 5-HT-induced apnea experiments before (baseline; $N=30$ ) and after ICV injections of various concentrations of dronabinol $(100,10,1$ or $0.1 \mu \mathrm{g} ; N=6$ for each dose) or vehicle (DMSO; $N=6)$. ICV injections of dronabinol at any concentration did not significantly $(p=0.19)$ attenuate reflex apneas. Data (mean \pm SEM) were analyzed using mixed model analysis with a repeated/fixed measure (ICV treatment)

not significantly $\left(F_{5}, 32.7=1.89, p=0.12\right)$ altered by $100 \mu \mathrm{g} \quad(0.84 \pm 0.06$ seconds, $N=6), 10 \mu \mathrm{g} \quad(0.84 \pm$ 0.08 seconds, $N=6), 1 \mu \mathrm{g}(0.75 \pm 0.03$ seconds, $N=6)$, or $0.1 \mu \mathrm{g}(0.86 \pm 0.06$ seconds, $N=6)$ ICV injection of dronabinol, or ICV injection of vehicle (DMSO; $0.99 \pm$ 0.11 seconds, $N=6$; Fig. 2). Coefficient of variation of 30 breath durations before (pre) and after (post) 5-HT infusion was quantified as a measurement of respiratory instability (Fig. 3) [35]. There was no ICV treatment main effect $\left(F_{5}, 11.0=1.03, p=0.45\right)$ or interaction between ICV treatment and time $\left(F_{5,11.0}=1.01, p=0.46\right)$. There was a main effect of time $\left(F_{1}, 14.5=87.7, p<0.01\right)$;

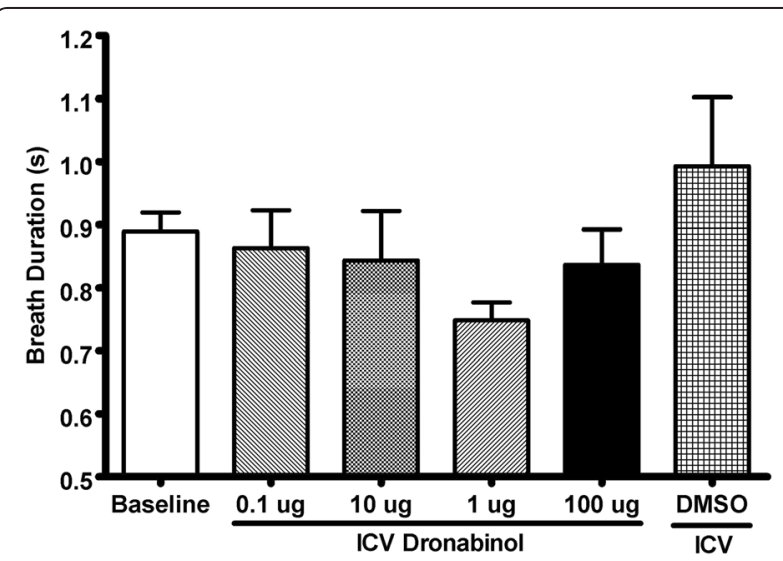

Fig. 2 Breath duration quantified prior to 5-HT infusion before (baseline; $N=30$ ) and after ICV injections of various concentrations of dronabinol $(100,10,1$ or $0.1 \mu \mathrm{g} ; N=6$ for each dose) or vehicle (DMSO; $N=6)$. There were no significantly $(p=0.12)$ differences in breath duration in the treatment groups. Data (mean \pm SEM) were analyzed using mixed model analysis with a repeated/fixed measure (ICV treatment) 


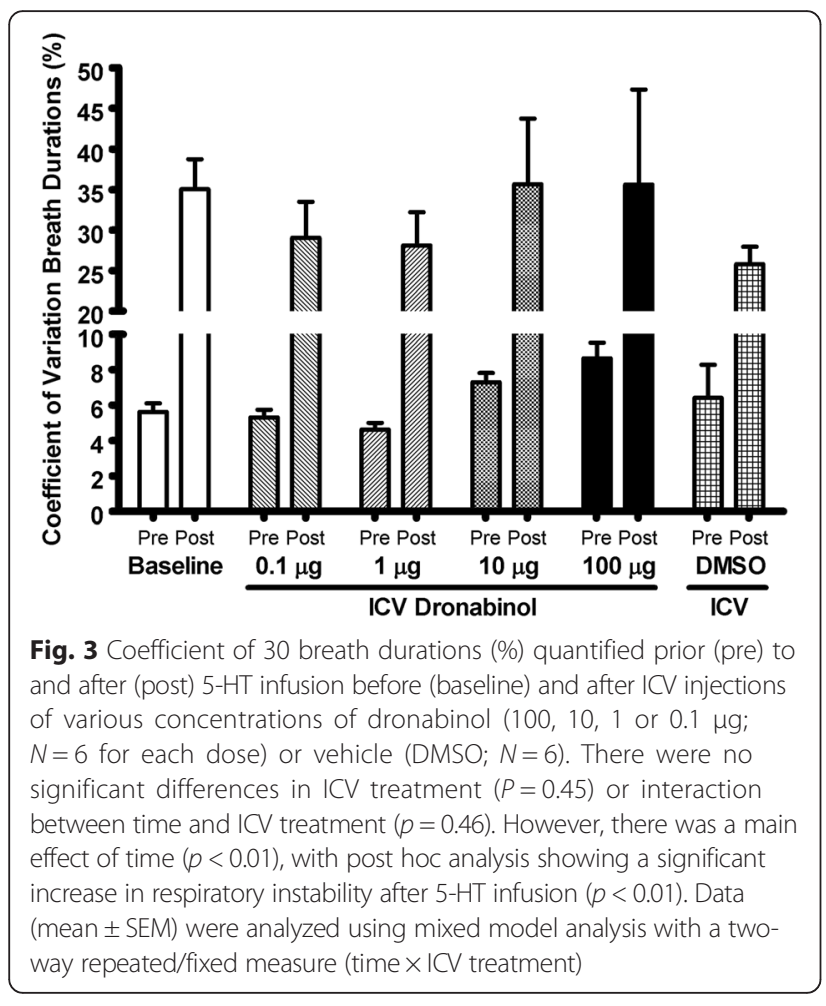

breathing was more unstable following 5-HT infusion compared to before infusion ( $p<0.01$; Fig. 3$)$.

Genioglossus activity was measured at the start of inspiration (Phasic EMGgg) and at the end of expiration (tonic EMGgg) prior to reflex apneas (Fig. 4). ICV Injections of $100 \mu \mathrm{g}(0.89 \pm 0.28$ a.u., $N=6), 10 \mu \mathrm{g}(1.17 \pm 0.41$ a.u., $N=6), 1 \mu \mathrm{g}(0.59 \pm 0.12$ a.u., $N=6)$, or $0.1 \mu \mathrm{g}(0.93 \pm$ 0.24 a.u., $N=6$ ) of dronabinol, or injection of vehicle (DMSO; $0.63 \pm 0.11$ a.u., $N=6$ ) did not significantly
$\left(F_{4,9.50}=0.94, p=0.48\right.$ for main effect of "treatment" $)$ alter phasic EMGgg (Fig. 4a). Similarly, ICV injections of $100 \mu \mathrm{g} \quad(0.97 \pm 0.13$ a.u., $N=6), 10 \mu \mathrm{g} \quad(1.46 \pm$ 0.20 a.u., $N=6), 1 \mu g(1.33 \pm 0.45$ a.u., $N=6)$, or $0.1 \mu \mathrm{g}(1.23 \pm 0.29$ a.u., $N=6)$ of dronabinol, or injection of vehicle (DMSO; $1.35 \pm 0.46$ a.u., $N=6$ ) did not significantly $\left(F_{4}, 7.96=1.22, p=0.37\right.$ for main effect of "treatment") alter tonic EMGgg (Fig. 4b).

\section{Discussion}

With the increasing prevalence [1], comorbidity with other diseases [3-5], and a lack of tolerable and effective treatment options $[2,6]$, OSA is a significant health problem. An impediment to effective treatments of OSA is insufficient knowledge of peripheral and central neural mechanisms of respiratory control, especially during sleep. Though we have shown previously that modulation of vagal afferents via activation of $\mathrm{CB}$ receptors located on nodose ganglion neurons can attenuate reflex apneas $[14,15]$, it was uncertain what role central CB receptors play in respiratory pattern control. Here we show that ICV injection of dronabinol, a non-specific agonist of $\mathrm{CB}_{1}$ and $\mathrm{CB}_{2}$ receptors, does not attenuate peripherally-induced reflex apneas.

Vagal afferent neurons, which relay important information about respiratory drive and upper airway muscle tone $[16,17,36]$, provide input to the excitatory or inhibitory neurons located in nucleus of the solitary tract (NTS) [37, 38]. The NTS projects to the respiratory centers of the brainstem, including the hypoglossal nucleus (XII) and the rostral ventrolateral medulla (RVLM) $[36,39]$. The NTS contains a variety of neuronal populations that fire at distinct points in the expiratoryinspiratory phases of breathing [40]. Reflex apneas are
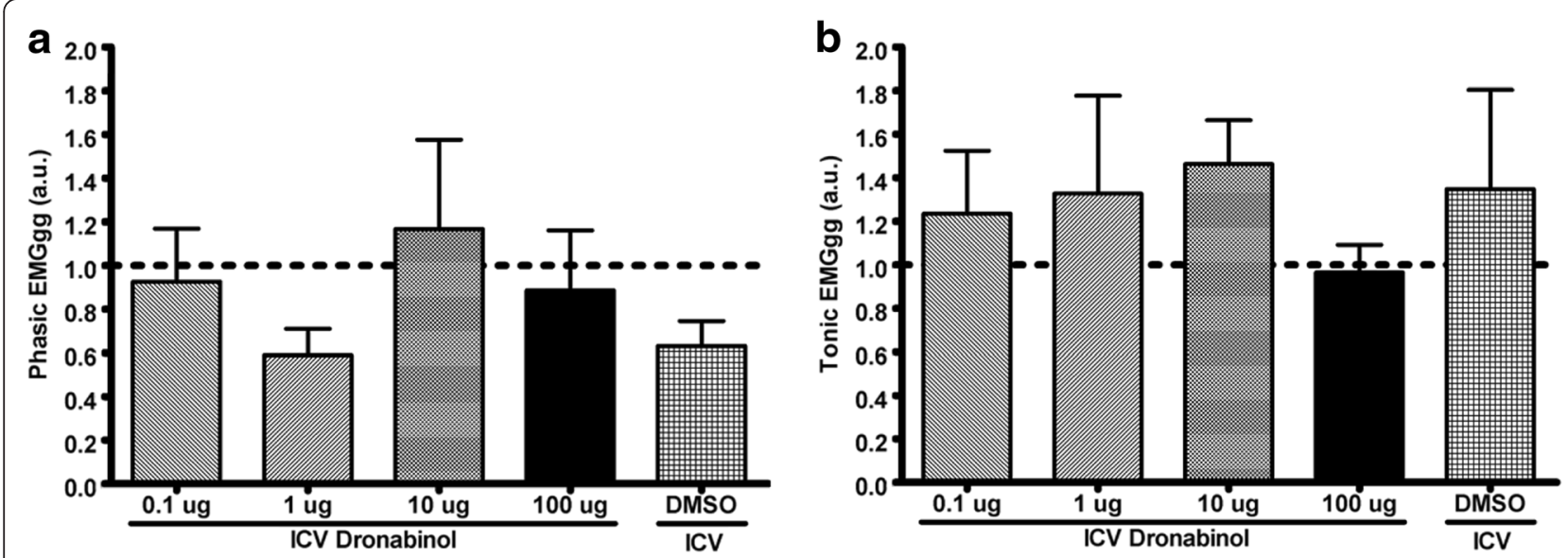

Fig. 4 Phasic (a) and tonic (b) genioglossus electrogram amplitude (arbitrary units, a.u.; dotted line corresponds to baseline EMGgg) quantified after ICV injections of various concentrations of dronabinol (100, 10, 1 or $0.1 \mu \mathrm{g} ; \mathrm{N}=6$ for each dose) or vehicle (DMSO; $N=6)$. There were no significant differences in phasic $(p=0.48)$ or tonic $(p=0.37)$ EMGgg in the treatment groups. Data (mean \pm SEM) were analyzed using mixed model analysis with a repeated/fixed measure (ICV treatment) 
induced peripherally via the vagus nerve by pharmacologically activating excitatory receptors located on nodose ganglia, or by mechanically activating stretch receptors located in the lung [16, 41]. Reflex apneas are also induced "downstream" by activation of glutamatergic receptors in the NTS [42-45]. Conversely, vagally-induced apnea can be reversed by microinjection of a GABA agonist [46], or a glutamatergic NMDA antagonist [45], into the NTS. Vagal afferents also synapse in regions of the NTS that modulate sympathetic activity, with activation of vagal afferents not only inducing apnea, but decreasing heart rate and blood pressure [41]. This trifecta of responses, known as the Bezold-Jarisch reflex, is modulated by different regions of the NTS, and these regions, when activated or inhibited, induce variable responses in blood pressure, heart rate, and breathing [45-47]. The NTS contains both $\mathrm{CB}_{1}$ and $\mathrm{CB}_{2}$ receptors that, when activated, inhibit or promote NTS activity, and attenuate other vagally-mediated behaviors $[26,27,48-51] . \mathrm{CB}_{1}$ activation decreases glutamate release in the NTS [51], thus $\mathrm{CB}_{1}$ activation would have the effect of suppressing apneas. $\mathrm{CB}_{1}$ activation also disinhibits second order NTS neurons by pre-synaptically decreasing release of GABA [51-53], thus $\mathrm{CB}_{1}$ activation would have the opposite effect of potentiating apneas. It might be plausible that the dual effects of $\mathrm{CB}_{1}$ activation occurred, with the consequence of neither suppressing nor potentiating apneas.

Moreover, the XII, which modulates the phasic and tonic activation of the genioglossus muscle [36], also contains $\mathrm{CB}_{1}$ receptors $[23,25,28,54,55]$, of which the physiologic role is unclear. $\mathrm{CB}_{1}$ activation in the XII is known to disinhibit XII by preventing release of glycine, an inhibitory neurotransmitter $[25,54]$. In fact, a CB agonist microinjected in the XII activated the genioglossus in awake, but not sleeping, rats [55]. A recent report showed cardiorespiratory anomalies, including unstable breathing and apneas, in $\mathrm{CB}_{1}$ knockout mice [56]. We hypothesized that the activation of $\mathrm{CB}$ receptors located at crucial respiratory centers in the brainstem would modulate reflex apneas and increase genioglossus activity; however, we saw no effect of a centrally-administered $C B$ agonist, dronabinol.

The present work focused on global activation of $\mathrm{CB}$ receptors located in the brain, which mimicked patients undergoing dronabinol treatment [12], and did not elucidate any specific local effects of the respiratory centers of the brainstem. Due to the variability of Bezold-Jarisch reflex responses to NTS activation or inhibition, and the location of $\mathrm{CB}$ receptors on both excitatory and inhibitory neurons of the NTS, it is possible that non-specific and global activation of central $\mathrm{CB}$ receptors via $\mathrm{ICV}$ injection of dronabinol led to multiple and potentially opposing responses, masking any specific local effects.
Therefore no physiologic response was observed. For example, Padley et al. induced apnea by microinjecting a $\mathrm{CB}_{1}$ agonist centrally into the RVLM, which sends projections to inhibitory neurons located in the respiratory centers of the brainstem [39]. Also, injection of CBs peripherally in the nodose ganglia increased genioglossus activity, presumably through disinhibition of parasympathetic input into respiratory centers of the brain [15]. Carley et al. showed respiratory stability with intraperitoneal injections of dronabinol, which would involve both peripheral and central CB receptors [13]. Moreover, low and high doses of CBs are known to have biphasic effects [31, 57]; however, we saw no changes in apnea response at low or high doses of dronabinol. Since CB receptors are widely distributed in the brain, on both excitatory and inhibitory neurons, and are activated differentially by different concentrations of CBs, specific microinjections in the NTS or XII will need to be completed to see if CBs have any effect on breathing and genioglossus activity in rats.

\section{Conclusions}

In conclusion, we show that ICV injections of dronabinol, a non-specific CB agonist, had no effect on 5-HTinduced reflex apnea, and had no effect on genioglossus activity. These results suggest that central $\mathrm{CB}$ receptors have a minimal or no effect on breathing when activated globally; however, there might be specific local effects of CBs due to the diverse population of neuronal inputs and outputs of the NTS. Previous work showing stabilization of breathing from CBs might be derived from activation of $\mathrm{CB}$ receptors located on peripheral nerves [13-15], suggesting that pharmacotherapies targeting only peripheral CB receptors for OSA treatment might be sufficient. Future work will concentrate on elucidating specific local effects of CBs on breathing in the NTS and XII.

\section{Abbreviations}

5-HT: serotonin; a.u.: arbitrary units; $\mathrm{CB}$ : cannabinoid; $\mathrm{CB}_{1}$ : cannabinoid type 1 receptor; $\mathrm{CB}_{2}$ : cannabinoid type 2 receptor; DMSO: dimethyl sulfoxide;

ICV: intracerebroventricular; NTS: nucleus of the solitary tract;

OSA: obstructive sleep apnea; RVLM: rostral ventrolateral medulla;

XII: hypoglossal nucleus.

\section{Competing interests}

DWC has the following interests: owns stocks or shares (Cortex

Pharmaceuticals); patents and patent applications assigned to the University of Illinois at Chicago (US 8,207,230 "Functional role for cannabinoids in autonomic stability during sleep", US 8,076,315 "Pharmacological treatments for sleep disorders (apnoea) with prostanoid receptor antagonists", US 8,053,413 "Methods for treating sleep disorders by cholecystokinin (CCK) receptor B antagonists", US 7,705,039 "Method for treating sleep apnea", US 7,160,898 "Pharmacological treatment for sleep apnea", US 6,974,814 "Neuropharmacological treatment of sleep-related breathing disorders", US 6,727,242 "Pharmacological treatment for sleep apnea", US 6,555,564 "Neuropharmacological treatments of sleep-related breathing disorders", US 6,331,536 "Pharmacological treatment for sleep apnea", US 8,775,340 "Detection and prediction of physiological events in people with sleep 
disordered breathing using a LAMSTAR neural network", US 20140045755 "METHODS FOR TREATING SLEEP DISORDERS BY CHOLECYSTOKININ (CCK) RECEPTOR B ANTAGONISTS", US 20120108570 "Pharmacological Treatment for Sleep Apnea", US 20120010198 "Methods for Treating Sleep Disorders by Cholecystokinin (CCK) Receptor B Antagonists" US 20100137251 "Functional Role for Cannabinoids in Autonomic Stability During Sleep", US 20090221658 "Pharmacological Treatment for Sleep Apnea", US 20090005357 "Pharmacological Treatment for Sleep Apnea", US 20080261922 "Pharmacological Treatments for Sleep Disorders (Apnoea) With Prostanoid Receptor Antagonists", US 20080200367 "Compositions and Methods for Treating Sleep Disorders", US 20070123517 "Pharmacological treatment for sleep apnea", US 20060241164 "Pharmacological treatment for sleep apnea", US 20040127572 "Functional role for cannabinoids in autonomic stability during sleep", US 20030236228 "Neuropharmacological treatment of sleep-related breathing disorders", US 20030130266 "Pharmacological treatment for sleep apnea", US 20020086870 "Pharmacological treatment for sleep apnea", US 20110251985 "Detection and Prediction of Physiological Events in People with Sleep Disordered Breathing Using a LAMSTAR Neural Network", US 20120231083 "SUSTAINED RELEASE CANNABINOID MEDICAMENTS", ES 2423412 "Composiciones y métodos para tratar los trastornos del sueño", JP 2010168404 "PHARMACOLOGICAL TREATMENT OF SLEEP APNEA SYNDROME", JP 2010059195 "PHARMACEUTICAL AGENT WITH SEROTONIN-RELATED ACTIVITY FOR TREATMENT FOR SLEEP APNEA", EP 1898921 "COMPOSITIONS AND METHODS FOR TREATING SLEEP DISORDERS", EP 1868602 "PHARMACOLOGICAL TREATMENT FOR SLEEP APNEA", WO WO/2007/047575 "PHARMACOLOGICAL TREATMENTS FOR SLEEP-RELATED BREATHING DISORDERS", WO WO/2007/047372 "PHARMACOLOGICAL TREATMENTS FOR SLEEP DISORDERS (APNOEA) WITH PROSTANOID RECEPTOR ANTAGONISTS", WO WO/2007/047577 "USE OF CALCITONINRELATED PEPTIDE (CGRP) ANTAGONISTS OR RELEASE INHIBITORS FOR THE TREATMENT OF SLEEP-RELATED BREATHING DISORDERS", ES 2267253 "AGENTES CON ACTIVIDAD RELACIONADA CON LA SEROTONINA PARA EL TRATAMIENTO DE LA APNEA DEL SUEÑO", WO WO/2006/133197 "COMPOSITIONS AND METHODS FOR TREATING SLEEP DISORDERS", WO WO/2006/113448 "PHARMACOLOGICAL TREATMENT FOR SLEEP APNEA", CA 2603920 "PHARMACOLOGICAL TREATMENT FOR SLEEP APNEA", MX PA/a/2005/ 004448 "USE OF SEROTONIN RECEPTOR ANTAGONISTS FOR THE TREATMENT OF SLEEP APNEA", CN 1708302 "Pharmacological treatment for sleep apnea", BR PI0315846 "Tratamento farmacológico para apnéia do sono", EP 1572202 "USE OF SEROTONIN RECEPTOR ANTAGONISTS FOR THE TREATMENT OF SLEEP APNEA", WO WO/2004/041272 "USE OF SEROTONIN RECEPTOR ANTAGONISTS FOR THE TREATMENT OF SLEEP APNEA", CA 2503718 "USE OF SEROTONIN RECEPTOR ANTAGONISTS FOR THE TREATMENT OF SLEEP APNEA", EP 1372638 "CANNABINOIDS FOR THE TREATMENT OF BREATHING DISORDERS DURING SLEEP", WO WO/2002/080903 "FUNCTIONAL ROLE FOR CANNABINOIDS IN AUTONOMIC STABILITY DURING SLEEP", CA 2443105 "FUNCTIONAL ROLE FOR CANNABINOIDS IN AUTONOMIC STABILITY DURING SLEEP", EP 1066036 "AGENTS WITH SEROTONIN-RELATED ACTIVITY FOR THE TREATMENT FOR SLEEP APNEA", WO WO/2000/051590 "NEUROPHARMACOLOGICAL TREATMENT OF SLEEP-RELATED BREATHING DISORDERS", WO WO/1999/043319 "AGENTS WITH SEROTONIN-RELATED ACTIVITY FOR THE TREATMENT FOR SLEEP APNEA", CA 2321900 "AGENTS WITH SEROTONIN-RELATED ACTIVITY FOR THE TREATMENT FOR SLEEP APNEA", WO WO/2012/068516 "LOW DOSE CANNABINOID MEDICAMENTS", WO WO/2011/063164 "SUSTAINED RELEASE CANNABINOID MEDICAMENTS", WO WO/2010/080405 "DETECTION AND PREDICTION OF PHYSIOLOGICAL EVENTS IN PEOPLE WITH SLEEP DISORDERED BREATHING USING A LAMSTAR NEURAL NETWORK"); completed (not current) research grants from commercial organizations (Glaxo-Wellcome "Effects of adenosine A1 receptor agonists on sleep apnea" 03/96 - 11/96, Glaxo-Wellcome "A single center, randomized double-blind, placebo controlled, two period crossover study to investigate the efficacy of intravenous GR79236 in patients with sleep apnea" 11/98 - 10/99, Synthelabo Research "Effects of serotonin antagonists on sleep apneas in rats" 4/99 - 9/99, Organon Pharmaceutical "A proof of concept trial for Remeron in sleep apnea syndrome" 12/99 - 12/01, BTG International "Pharmacologic treatment of sleep apnea" 04/04 - 03/06, BTG International "Pharmacologic treatment for sleep apnea (clinical pilot), 10/05 - 09/07, Organon Pharmaceutical "A randomized, double-blind, placebo-contrtolled, multicenter, parallel-group dose ranging clinical trial to assess the efficacy and safety of Org4419-2 in the treatment of obstructive sleep apnea/hypopnea syndrome" 09/05 - 09/06, SteadySleep Rx "Randomized, double-blind, placebo controlled study of the safety and efficacy of Marinol in patients with sleep apnea" 10/08 - 10/12). This does not alter our adherence to PLOS ONE policies on sharing data and materials.

\section{Authors' contributions}

Conceived and designed the experiments: MWC and DWC. Performed the experiments: MWC. Analyzed the data: MWC. Contributed reagents/ materials/analysis tools: DWC. Contributed to the writing of the manuscript: MWC and DWC. Both authors read and approved the final manuscript.

\section{Acknowledgments}

We would like to thank Miodrag "Misha" Radulovacki, M.D., Ph.D., from University of Illinois at Chicago, for his guidance and mentorship during this project. We also like to thank Barth B. Riley, Ph.D., from the University of Illinois at Chicago, for his help statistical guidance. This study was supported by National Institutes of Health Grant 1UM1HL112856.

\section{Author details}

'Center for Narcolepsy, Sleep and Health Research, University of Illinois at Chicago, 845 South Damen Avenue (M/C 802), Chicago, IL 60612, USA. ${ }^{2}$ Department of Biobehavioral Health Science, University of Illinois at Chicago, 845 South Damen Avenue (M/C 802), Chicago, IL 60612, USA. ${ }^{3}$ Department of Medicine, University of Illinois at Chicago, 1853 West Polk Street (M/C 784), Chicago, IL 60612, USA.

\section{Received: 12 January 2016 Accepted: 2 April 2016}

Published online: 02 May 2016

\section{References}

1. Peppard PE, Young T, Barnet JH, Palta M, Hagen EW, Hla KM. Increased Prevalence of Sleep-Disordered Breathing in Adults. Am J Epidemiol. 2013;177(9):1006-14.

2. Weaver TE, Calik MW, Farabi SS, Fink AM, Galang-Boquiren MT, Kapella MC, Prasad B, Carley DW. Innovative treatments for adults with obstructive sleep apnea. Nat Sci Sleep. 2014;6:137-47.

3. Marshall NS, Wong KK, Liu PY, Cullen SR, Knuiman MW, Grunstein RR. Sleep apnea as an independent risk factor for all-cause mortality: the Busselton Health Study. Sleep. 2008;31(8):1079-85.

4. Young T, Finn L, Peppard PE, Szklo-Coxe M, Austin D, Nieto FJ, Stubbs R, Hla KM. Sleep disordered breathing and mortality: eighteen-year follow-up of the Wisconsin sleep cohort. Sleep. 2008;31(8):1071-8.

5. Young T, Peppard PE, Gottlieb DJ. Epidemiology of obstructive sleep apnea: a population health perspective. Am J Respir Crit Care Med. 2002;165(9):1217-39.

6. Smith I, Lasserson TJ, Wright J. Drug therapy for obstructive sleep apnoea in adults. Cochrane Database Syst Rev. 2006;2:CD003002.

7. Mukhopadhyay S, Shim JY, Assi AA, Norford D, Howlett AC. CB(1) cannabinoid receptor-G protein association: a possible mechanism for differential signaling. Chem Phys Lipids. 2002;121(1-2):91-109.

8. Carley DW, Radulovacki M. Pharmacology of vagal afferent influences on disordered breathing during sleep. Respir Physiol Neurobiol. 2008;164(1-2):197-203.

9. Miller LK, Devi LA. The highs and lows of cannabinoid receptor expression in disease: mechanisms and their therapeutic implications. Pharmacol Rev. 2011;63(3):461-70.

10. Pacher P, Batkai $S$, Kunos $G$. The endocannabinoid system as an emerging target of pharmacotherapy. Pharmacol Rev. 2006;58(3):389-462.

11. Pertwee RG. The diverse $C B 1$ and $C B 2$ receptor pharmacology of three plant cannabinoids: delta9-tetrahydrocannabinol, cannabidiol and delta9tetrahydrocannabivarin. Br J Pharmacol. 2008;153(2):199-215.

12. Prasad B, Radulovacki MG, Carley DW. Proof of concept trial of dronabinol in obstructive sleep apnea. Front Psychiatry. 2013;4:1.

13. Carley DW, Paviovic S, Janelidze M, Radulovacki M. Functional role for cannabinoids in respiratory stability during sleep. Sleep. 2002;25(4):391-8.

14. Calik MW, Carley DW. Cannabinoid type 1 and type 2 receptor antagonists prevent attenuation of serotonin-induced reflex apneas by dronabinol in Sprague-Dawley rats. PLoS One. 2014;9(10):e111412.

15. Calik MW, Radulovacki M, Carley DW. Intranodose ganglion injections of dronabinol attenuate serotonin-induced apnea in Sprague-Dawley rat. Respir Physiol Neurobiol. 2014;190:20-4.

16. Kaczynska K, Szereda-Przestaszewska M. Nodose ganglia-modulatory effects on respiration. Physiol Res. 2013;62(3):227-35. 
17. Chang RB, Strochlic DE, Williams EK, Umans BD, Liberles SD. Vagal Sensory Neuron Subtypes that Differentially Control Breathing. Cell. 2015;161(3):622-33.

18. Yoshioka M, Goda Y, Togashi H, Matsumoto M, Saito H. Pharmacological characterization of 5-hydroxytryptamine-induced apnea in the rat. J Pharmacol Exp Ther. 1992;260(2):917-24.

19. Liu BY, Lin YJ, Lee HF, Ho CY, Ruan T, Kou YR. Menthol suppresses laryngeal Cfiber hypersensitivity to cigarette smoke in a rat model of gastroesophageal reflux disease: the role of TRPM8. J Appl Physiol. 2015;118(5):635-45.

20. Liu BY, Tsai TL, Ho CY, Lu SH, Lai CJ, Kou YR. Role of TRPA1 and TRPV1 in the ROS-dependent sensory irritation of superior laryngeal capsaicinsensitive afferents by cigarette smoke in anesthetized rats. Pulm Pharmacol Ther. 2013;26(3):364-72.

21. Parhizgar F, Nugent $K$, Raj R. Obstructive sleep apnea and respiratory complications associated with vagus nerve stimulators. J Clin Sleep Med. 2011;7(4):401-7

22. Huestis MA. Human cannabinoid pharmacokinetics. Chem Biodivers. 2007;4(8):1770-804.

23. Herkenham M. Characterization and localization of cannabinoid receptors in brain: an in vitro technique using slide-mounted tissue sections. NIDA Res Monogr. 1991;112:129-45.

24. Herkenham M, Lynn AB, Little MD, Johnson MR, Melvin LS, de Costa BR, et al. Cannabinoid receptor localization in brain. Proc Natl Acad Sci U S A. 1990;87(5):1932-6.

25. Mukhtarov M, Ragozzino D, Bregestovski P. Dual Ca2+ modulation of glycinergic synaptic currents in rodent hypoglossal motoneurones. J Physiol. 2005;569(Pt 3):817-31.

26. Rohof WO, Aronica E, Beaumont H, Troost D, Boeckxstaens GE. Localization of mGluR5, GABAB, GABAA, and cannabinoid receptors on the vago-vagal reflex pathway responsible for transient lower esophageal sphincter relaxation in humans: an immunohistochemical study. Neurogastroenterol Motil. 2012:24(4):383-e173.

27. Van Sickle MD, Duncan M, Kingsley PJ, Mouihate A, Urbani P, Mackie K, Stella N, Makriyannis A, Piomelli D, Davison JS, et al. Identification and functional characterization of brainstem cannabinoid CB2 receptors. Science. 2005:310(5746):329-32

28. Glass M, Dragunow M, Faull RL. Cannabinoid receptors in the human brain: a detailed anatomical and quantitative autoradiographic study in the fetal, neonatal and adult human brain. Neuroscience. 1997;77(2):299-318.

29. Howlett AC, Barth F, Bonner TI, Cabral G, Casellas P, Devane WA, Felder CC, Herkenham M, Mackie K, Martin BR, et al. International Union of Pharmacology. $X X V I I$. Classification of cannabinoid receptors. Pharmacol Rev. 2002;54(2):161-202

30. Wilson RI, Nicoll RA. Endocannabinoid signaling in the brain. Science. 2002;296(5568):678-82.

31. Braida D, losue S, Pegorini S, Sala M. Delta9-tetrahydrocannabinol-induced conditioned place preference and intracerebroventricular self-administration in rats. Eur J Pharmacol. 2004;506(1):63-9.

32. Manzanares J, Corchero J, Fuentes JA. Opioid and cannabinoid receptormediated regulation of the increase in adrenocorticotropin hormone and corticosterone plasma concentrations induced by central administration of delta(9)-tetrahydrocannabinol in rats. Brain Res. 1999;839(1):173-9.

33. Verty AN, McFarlane JR, McGregor IS, Mallet PE. Evidence for an interaction between CB1 cannabinoid and oxytocin receptors in food and water intake. Neuropharmacology. 2004;47(4):593-603.

34. Wakley AA, Craft RM. Antinociception and sedation following intracerebroventricular administration of Delta(9)-tetrahydrocannabinol in female vs. male rats. Behav Brain Res. 2011;216(1):200-6.

35. Topchiy I, Radulovacki M, Waxman J, Carley DW. Cardiorespiratory effects of intertrigeminal area stimulation in vagotomized rats. Brain Res. 2009:1250:120-9.

36. Haji A, Takeda R, Okazaki M. Neuropharmacology of control of respiratory rhythm and pattern in mature mammals. Pharmacol Ther. 2000;86(3):277-304.

37. Berthoud HR, Neuhuber WL. Functional and chemical anatomy of the afferent vagal system. Auton Neurosci. 2000;85(1-3):1-17.

38. Mazzone SB, Canning BJ. Central nervous system control of the airways: pharmacological implications. Curr Opin Pharmacol. 2002;2(3):220-8

39. Padley JR, Li Q, Pilowsky PM, Goodchild AK. Cannabinoid receptor activation in the rostral ventrolateral medulla oblongata evokes cardiorespiratory effects in anaesthetised rats. Br J Pharmacol. 2003;140(2):384-94.
40. Subramanian HH, Chow CM, Balnave RJ. Identification of different types of respiratory neurones in the dorsal brainstem nucleus tractus solitarius of the rat. Brain Res. 2007;1141:119-32.

41. Zoccal DB, Furuya WI, Bassi M, Colombari DS, Colombari E. The nucleus of the solitary tract and the coordination of respiratory and sympathetic activities. Front Physiol. 2014;5:238

42. Almado $\mathrm{CE}$, Machado BH. Respiratory and autonomic responses to microinjection of NMDA and AMPA into the commissural subnucleus of the NTS of awake rats. Brain Res. 2005;1063(1):59-68.

43. Gourine AV, Dale N, Korsak A, Llaudet E, Tian F, Huckstepp R, Spyer KM. Release of ATP and glutamate in the nucleus tractus solitarii mediate pulmonary stretch receptor (Breuer-Hering) reflex pathway. J Physiol. 2008:586(16):3963-78

44. Vardhan A, Kachroo A, Sapru HN. Excitatory amino acid receptors in the nucleus tractus solitarius mediate the responses to the stimulation of cardiopulmonary vagal afferent C fiber endings. Brain Res. 1993;618(1):23-31.

45. Chianca Jr DA, Machado BH. Microinjection of NMDA antagonist into the NTS of conscious rats blocks the Bezold-Jarisch reflex. Brain Res. 1996;718(1-2):185-8

46. Seifert $E$, Trippenbach T. Baclofen attenuates cardiorespiratory effects of vagal C fiber stimulation in rats. Can J Physiol Pharmacol. 1995;73(10):1485-94.

47. Verberne AJ, Guyenet PG. Medullary pathway of the Bezold-Jarisch reflex in the rat. Am J Physiol. 1992;263(6 Pt 2):R1195-202.

48. Van Sickle MD, Oland LD, Ho W, Hillard CJ, Mackie K, Davison JS, Sharkey KA. Cannabinoids inhibit emesis through $C B 1$ receptors in the brainstem of the ferret. Gastroenterology. 2001;121(4):767-74.

49. Van Sickle MD, Oland LD, Mackie K, Davison JS, Sharkey KA. Delta9tetrahydrocannabinol selectively acts on CB1 receptors in specific regions of dorsal vagal complex to inhibit emesis in ferrets. Am J Physiol Gastrointest Liver Physiol. 2003;285(3):G566-76.

50. Sharkey KA, Cristino L, Oland LD, Van Sickle MD, Starowicz K, Pittman QJ, Guglielmotti V, Davison JS, Di Marzo V. Arvanil, anandamide and Narachidonoyl-dopamine (NADA) inhibit emesis through cannabinoid CB1 and vanilloid TRPV1 receptors in the ferret. Eur J Neurosci. 2007:25(9):2773-82

51. Seagard JL, Dean C, Patel S, Rademacher DJ, Hopp FA, Schmeling WT, Hillard CJ. Anandamide content and interaction of endocannabinoid/GABA modulatory effects in the NTS on baroreflex-evoked sympathoinhibition. Am J Physiol Heart Circ Physiol. 2004;286(3):H992-1000.

52. Chen CY, Bonham AC, Dean C, Hopp FA, Hillard CJ, Seagard JL. Retrograde release of endocannabinoids inhibits presynaptic GABA release to secondorder baroreceptive neurons in NTS. Auton Neurosci. 2010;158(1-2):44-50.

53. Seagard JL, Hopp FA, Hillard CJ, Dean C. Effects of endocannabinoids on discharge of baroreceptive NTS neurons. Neurosci Lett. 2005:381(3):334-9.

54. Lozovaya N, Mukhtarov M, Tsintsadze T, Ledent C, Burnashev N, Bregestovski P. Frequency-Dependent Cannabinoid Receptor-Independent Modulation of Glycine Receptors by Endocannabinoid 2-AG. Front Mol Neurosci. 2011:4:13.

55. Grace KP, Hughes SW, Horner RL. Identification of a pharmacological target for genioglossus reactivation throughout sleep. Sleep. 2014;37(1):41-50.

56. Silvani A, Berteotti C, Bastianini S, Cohen G, Lo Martire V, Mazza R, Pagotto U, Quarta C, Zoccoli G. Cardiorespiratory anomalies in mice lacking CB1 cannabinoid receptors. PLoS One. 2014;9(6):e100536.

57. Umathe SN, Manna SS, Jain NS. Involvement of endocannabinoids in antidepressant and anti-compulsive effect of fluoxetine in mice. Behav Brain Res. 2011;223(1):125-34. 